\title{
MAPEAMENTO DOS CONFLITOS DE USO NAS ÁREAS DE PRESERVAÇÃO PERMANENTE (APPS) DA MICROBACIA DO RIACHO DO RONCADOR, TIMON (MA)
}

\author{
MAPPING OF LAND USE CONFLICTS IN PERMANENT PRESERVATION AREAS \\ (PPAS) OF THE WATERSHED OF THE RONCADOR STREAM, TIMON (MA)
}

\author{
MAPEO DE LOS CONFLICTOS DE USO DEL SUELO EN ÁREAS DE \\ PRESERVACIÓN PERMANENTE (APPs) DE LA MICROCUENCA DEL ARROYO \\ DEL RONCADOR, TIMON (MA)
}
Josenete Assunção Cardoso - Universidade Federal do Piauí - Teresina - Piauí - Brasil
jsnt.cardoso@gmail.com

Cláudia Maria Sabóia de Aquino - Universidade Federal do Piauí - Teresina - Piauí -Brasil cmsaboia@gmail.com

\section{Resumo}

A expansão desordenada das atividades antrópicas tem se tornado cada vez mais preocupante, porque tem avançado sobre áreas reconhecidamente protetoras dos recursos naturais, dentre as quais destacam-se as Áreas de Preservação Permanente (APPs). Diante deste fato, o presente trabalho objetivou detectar as APPs da microbacia do riacho do Roncador (MBRR), em Timon (MA), em desacordo com a legislação ambiental. Os resultados foram obtidos a partir da sobreposição do mapa de uso e cobertura das terras, de 26 de outubro de 2011, e do mapa das APPs da MBRR, gerando um terceiro mapa: 0 de conflitos de uso. A pesquisa revelou que $9,2 \mathrm{~km}^{2}$ da área da MBRR correspondem a APPs. Destes, $0,3 \mathrm{~km}^{2}$ corresponde às APPs de nascentes; $8,0 \mathrm{~km}^{2}$, às APPs de margens; $0,6 \mathrm{~km}^{2}$, às APPs de reservatórios naturais (lagoas); e $0,3 \mathrm{~km}^{2}$ corresponde às APPs de reservatórios artificiais. Dos 9,2 km² de Área de Preservação Permanente da microbacia, 2,6 km² encontramse com pelo menos um uso, estando, portanto, em desacordo com a legislação ambiental, o que exige maior fiscalização e monitoramento no intuito de garantir a sua função ambiental.

Palavras-chave: uso e cobertura das terras, Áreas de Preservação Permanente, conflitos, Timon (MA).

\section{Abstract}

The disordered expansion human activities have become increasingly worrying because it has advanced on areas known to be protective of natural resources, among which stand out the Permanent Preservation Areas (PPAs). Considering this fact, the present work aimed to detect the PPAs of the creek's watershed Roncador (MBRR) in Timon (MA) in violation of environmental laws. The results were obtained from the overlay of use map and land cover, to October 26, 2011, and map of the PPAs MBRR generating a third map: the conflicts of use. The research revealed that an area of $9.2 \mathrm{~km}^{2}$ of MBRR correspond to an PPAs. Of these, $0.3 \mathrm{~km}^{2}$ correspond to the PPAs springs; $8.0 \mathrm{~km}^{2}$, the PPAs margins; $0.6 \mathrm{~km}^{2}$, the PPAs natural reservoirs (lagoons) and $0.3 \mathrm{~km}^{2}$ correspond to the PPAs artificial reservoirs. Of $9.2 \mathrm{~km}^{2}$ of watershed's PPAs, $2.6 \mathrm{~km}^{2}$ are with at least one use, sobeing thus at odds with environmental legislation. Which requires greater supervision and monitoring of the PPAs of watershed in order to ensure the environmental function.

Keywords: use and land cover, Permanent Preservation Areas, conflicts, Timon (MA).

\section{Resumen}

La expansión de las actividades humanas tiene se tornado cada vez más preocupante, ya que ha avanzado en las áreas conocidas de protección de los recursos naturales, entre los que podemos destacar las Áreas 
de Preservación Permanente (APPs). Teniendo en cuenta este hecho, el presente estudio tuvo como objetivo detectar la APP de la microcuenca del arroyo Roncador (MBRR), en Timon (MA), en violación de las leyes ambientales. Los resultados se obtuvieron a partir de la superposición de mapa de uso y cobertura del suelo, del 26 de octubre de 2011, y del mapa de las APPs de la MBRR, generando un tercer mapa:el de conflictos. La investigación reveló que el 9,2 $\mathrm{km}^{2}$ de APPs de la microcuenca corresponde a APPs. De ellos, el 0,3 $\mathrm{km}^{2}$ corresponden a las APPs de manantial; el $8 \mathrm{~km}^{2}$ de orillas; el 0,6 $\mathrm{km}^{2}$, a las APPs de reservorios naturales de APP (lagunas) y el $0,3 \mathrm{~km}^{2}$ corresponden a las APPs de reservorios artificiales. Del 9,2 $\mathrm{km}^{2}$, de APPs de la microcuenca, el 2,6 km² son al menos un uso estando, por lo tanto, en contradicción con la legislación ambiental, que requiere una mayor supervisión y control de las APPs de la microcuencas de la aplicación con el fin de garantizar función ambiental de la mismas.

Palabras clave: uso y cobertura de las tierras, Áreas de Preservación Permanente, conflictos, Timon (MA).

\section{Introdução}

A expansão das atividades antrópicas, ao longo dos tempos, provocou uma carga de impactos negativos decorrentes da exploração dos recursos da natureza, notadamente os recursos hídricos e suas zonas de recarga localizadas nas pequenas bacias de cabeceiras ou microbacias hidrográficas. Essa expansão vem se tornando cada vez mais preocupante, porque tem avançado sobre áreas reconhecidamente protetoras dos recursos naturais, comprometendo sua função ambiental.

Dentre as áreas consideradas protetoras dos recursos naturais destacam-se as Áreas de Preservação Permanente (APPs), que, segundo Magalhães e Ferreira (2000, p. 33), "têm papel vital dentro de uma microbacia porque são responsáveis pela manutenção, preservação e conservação dos ecossistemas e recursos naturais ali existentes”, tais como a água, o solo, a fauna e a flora. Na análise de Zanatta et al. (2012), as APPs são

áreas que apresentam alta vulnerabilidade ao desenvolvimento de processos erosivos como sulcos, ravinas, voçorocas, movimentos de massa e assoreamento dos corpos d' água, resultando na degradação dos recursos naturais e em sérios riscos à população. (Zanatta et al., 2012, p. 64)

As APPs foram oficialmente criadas pela Lei $\mathrm{n}^{0} 4.771$, de 15 de setembro de 1965, que instituiu o Código Florestal Brasileiro. Segundo o Código Florestal, citado na Legislação Brasileira sobre Meio Ambiente (Brasil, 2010), as APPs são

áreas protegidas, cobertas ou não por vegetação nativa, com a função ambiental de preservar os recursos hídricos, a paisagem, a estabilidade geológica, a biodiversidade, o fluxo gênico de fauna e flora, 
proteger o solo e assegurar o bem-estar das populações humanas. (Brasil, 2010, p. 24)

O Código Florestal foi, ao longo do tempo, atualizado pelas Leis $\mathrm{n}^{\mathrm{O}}$ 5.870/73 e $\mathrm{n}^{0}$ 7.803/89, pela Medida Provisória $\mathrm{n}^{0}$ 2.166-67, de 24/08/2001, e pelas Resoluções do Conselho Nacional do Meio Ambiente (CONAMA) $\mathrm{n}^{\circ} 302$ e $\mathrm{n}^{\mathrm{o}} 303$, de 20 de março de 2002, de modo que o mapeamento das APPs em uma microbacia hidrográfica, bem como o amparo legal para a sua preservação e recuperação, constituem os aspectos mais importantes voltados para a conservação dos recursos naturais presentes nessas áreas.

São APPs, conforme a legislação brasileira, as florestas e demais formas de vegetação natural localizadas conforme critérios descritos no Quadro1.

Quadro 1 - Dimensões mínimas de faixa marginal a serem preservadas

\begin{tabular}{|l|l|}
\hline $\begin{array}{l}\text { Cursos d'água (largura), nascentes, } \\
\text { reservatórios artificiais e lagoas }\end{array}$ & Faixa a ser preservada \\
\hline Até 10 metros & $30 \mathrm{~m}$ em cada margem \\
\hline Entre 10 e 50 metros & $50 \mathrm{~m}$ em cada margem \\
\hline Entre 50 e 200 metros & $100 \mathrm{~m}$ em cada margem \\
\hline Entre 200 e 600 metros & $200 \mathrm{~m}$ em cada margem \\
\hline Superior a 600 metros & $500 \mathrm{~m}$ em cada margem \\
\hline Nascentes & $50 \mathrm{~m}$ no entorno da nascente \\
\hline Reservatórios artificiais (em zona rural) & $15 \mathrm{~m}$ no entorno do reservatório \\
\hline Lagoas & $\begin{array}{l}50 \mathrm{~m} \text { em torno das lagoas ou lagos } \\
\text { naturais }\end{array}$ \\
\hline
\end{tabular}

Fonte: Resolução CONAMA n ${ }^{0} 302$ e 303/2002

São ainda APPs os topos de morros, montes, montanhas e serras; as encostas ou partes destas, com declividade superior a $45^{\circ}$, equivalente a $100 \%$ na linha de maior declive; as restingas; as bordas dos tabuleiros ou chapadas de altitude superior a $1.800 \mathrm{~m}$.

A análise da legislação, com base nas características do meio físico, é fundamental para a definição de limites ao uso e à ocupação do solo em áreas de reconhecida qualidade ambiental, em que seu mapeamento orienta quanto ao reconhecimento daquelas que devem ser as prioritárias para serem preservadas e/ou recuperadas, a exemplo das APPs. 
Destaca-se nesse processo o uso das geotecnologias, que ultimamente têm sido imprescindíveis no detalhamento e mapeamento dos mais diversos conflitos decorrentes das transformações do espaço geográfico, permitindo às sociedades e aos seus gestores tomadas de decisão com base em diagnósticos mais precisos e, consequentemente, soluções mais efetivas.

Assim, este trabalho tem como objetivo: a) mapear as APPs da microbacia do riacho do Roncador (MBRR), localizada no município de Timon (MA), conforme Resolução CONAMA 302/2002, Resolução CONAMA 303/2002 e Código Florestal (1965); b) identificar as formas de uso e cobertura das terras da MBRR; c) realizar análise das APPs e das formas de uso e cobertura das terras, para fins de identificação de conflitos com base na legislação, gerando assim informações no intuito de subsidiar ações futuras de fiscalização, sua conservação e seu monitoramento ambiental.

\section{Material e métodos}

Área de estudo

De acordo com a Companhia de Pesquisa de Recursos Minerais CPRM (2011), na área de transição ou ecótono entre o Semiárido e a Amazônia úmida, onde está localizado o município de Timon, no Maranhão, Estado nordestino que menos se identifica com a maior característica da região Nordeste: a escassez de água -, insere-se a microbacia do riacho do

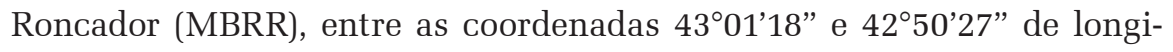
tude oeste, e $5^{\circ} 01^{\prime} 07^{\prime \prime}$ e $5^{\circ} 09^{\prime} 11^{\prime \prime}$ de latitude sul (Figura 1). Essa microbacia encontra-se inserida em sua totalidade na bacia hidrográfica do rio Parnaíba: uma bacia limítrofe com o Estado do Piauí e que possui, em território maranhense, uma área de $69.000,00 \mathrm{~km}^{2}$, correspondendo a aproximadamente 21,15 \% da área do Estado (IMESC, 2008).

Conforme critério proposto por Horton (1945), a área de estudo foi individualizada a partir dos divisores de água e, posteriormente, teve sua área mensurada em 200,2 km².

A MBRR no município de Timon apresenta grande atração para as populações das localidades próximas (IBGE, 1997; Maranhão, 2002), que utilizam para banhos naturais os diversos riachos que cortam seu território (IMESC, 2008), constituindo-se estes em uma das formas de lazer mais utilizadas por essas populações. 


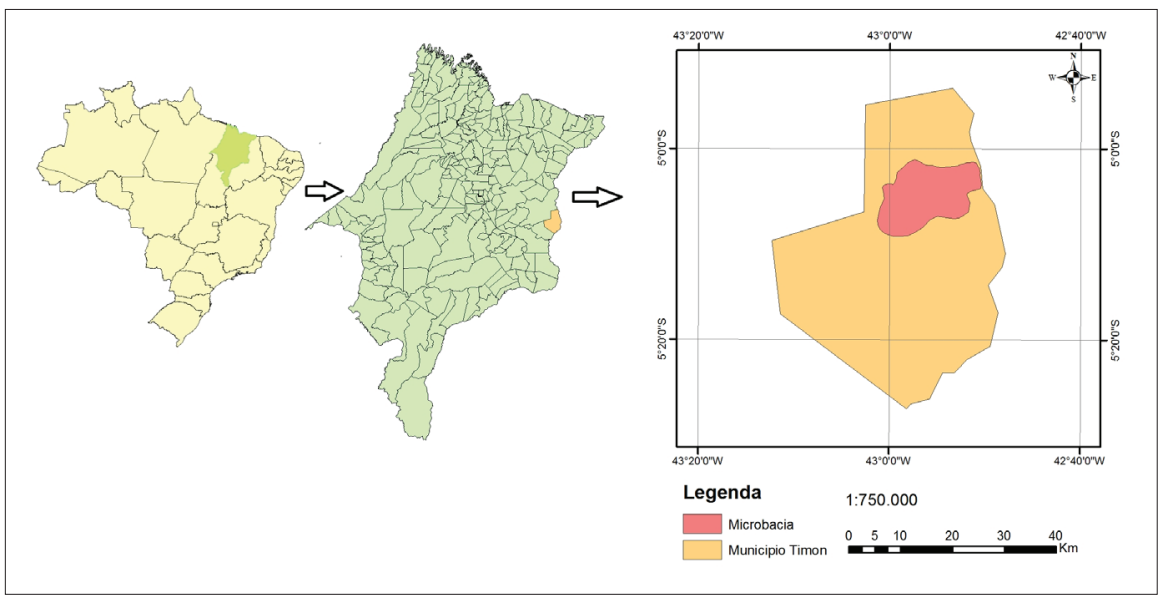

Figura 1 - Localização da microbacia do riacho do Roncador

Fonte: Base de dados do IBGE

Elaboração: Felipe Ferreira Monteiro

A área compreendida pela MBRR encontra-se inserida em sua totalidade no contexto geológico da província sedimentar do Meio-Norte, no sítio deposicional que corresponde ao da bacia do Parnaíba propriamente dita. As formações geológicas são compostas por arenitos, predominando na área de estudo as formações Pedra de Fogo (38,7\%) e Corda (33,0\%), datadas do Paleozoico (Permiano) e Mesozoico (Jurássico), respectivamente. As feições típicas são aquelas de bacias sedimentares, com vales pedimentados e superfícies estruturais pediplanadas convergindo para a calha fluvial (Brasil, 1973). Apresenta relevo plano a suave ondulado e elevado grau de homogeneidade, com cotas altimétricas variando de 69 a $240 \mathrm{~m}$.

Conforme a Empresa Brasileira de Pesquisa Agropecuária (EMBRAPA) (1986), as principais classes de solos encontradas na área da MBRR são Latossolos Amarelos, Plintossolos, Argissolos Vermelho-Amarelos e Neossolos Flúvicos, com predomínio dos Plintossolos (43,7\%) e Latossolos Amarelos (37,4\%). De acordo com a classificação climática de Köppen, citado em MARANHÃO (2002), apresenta clima Aw', ou seja, tropical chuvoso subúmido a úmido, com precipitações variando de 1.200 a $1400 \mathrm{~mm}$. As altas temperaturas durante todo o ano e a grande amplitude diária marcam o regime térmico da região, com variação anual de: mínima de $21,6^{\circ} \mathrm{C}$, média de $26,7^{\circ} \mathrm{C}$ e máxima de $32,9^{\circ} \mathrm{C}$ (CODEVASF, 
2006). Os campos, com presença de cerrado/caatinga com padrão arbóreo-arbustivo e a mata de cocais, compondo a vegetação ciliar, são as principais formações vegetais da área.

Metodologia e procedimentos empregados no trabalho

Durante a pesquisa, foram utilizadas as Cartas Topográficas, disponibilizadas pela Diretoria de Serviço Geográfico (DSG) e pelo Instituto Brasileiro de Geografia e Estatística (IBGE), na escala de 1:100.000, Folha SB 23 X-D-II, MI - 886 (Teresina - PI, 1984) e Folha SB 23 X-D-I, MI - 885 (Buriti Cortado - MA, 1974), todas com projeção Universal Transversa de Mercator (UTM), DATUM “Córrego Alegre” (MG); utilizaram-se imagens de alta resolução espacial do Satélite GeoEye, de 26 de outubro de 2011 (imagens multiespectrais com resolução espacial de 1,65m), disponíveis gratuitamente no sítio Google Earth, sendo utilizado o software ArcGis 9.3 para o processamento de dados espaciais.

Para a identificação das APPs em conflito de uso, as atividades envolvidas na pesquisa foram divididas em três etapas principais: i) mapeamento de uso e cobertura das terras da MBRR; ii) mapeamento das APPs; e iii) mapeamento dos conflitos de uso nas APPs.

\section{i) Mapeamento de uso e cobertura das terras da MBRR}

O mapeamento do uso e cobertura das terras da área foi feito manualmente através de imagens de alta resolução espacial extraídas do sítio Google Earth, do dia 26 de outubro de 2011, conforme critérios metodológicos abordados em Moreira et al. (2011). Com base no reconhecimento da área de estudo, foi feita a vetorização com polígonos em torno de cada fragmento de tipo de cobertura e uso das terras na área da MBRR, em ambiente ArcGis 9.3. Todos os polígonos foram salvos no formato $\mathrm{Kml}$ (Keyhole Markup Language), criando-se, posteriormente, um shapefile de polígonos pelo software ExpertGPS 3.81. As classes de uso e cobertura foram caracterizadas segundo três dos sete elementos interpretativos da classificação visual propostos por Novo (2010): a cor, a textura e a forma.

Para o mapeamento de uso e cobertura das terras da MBRR, utilizou-se como suporte metodológico a orientação do Manual Técnico de Uso da Terra do IBGE (2006), sendo identificadas as seguintes classes de uso e co- 
bertura das terras da MBRR: cobertura vegetal, solo exposto, agricultura, reflorestamento, edificação urbana/rural, mineração, loteamento, indústria e água, além do mapeamento de pontos notáveis, sendo estes as rodovias, a pista de pouso, a linha férrea, a linha de transmissão de energia da Companhia Hidrelétrica do São Francisco (CHESF) e o lixão da cidade.

\section{ii) Mapeamento das APPs}

Para o mapeamento das APPs, foram empregados os seguintes instrumentos legais:

a) Delimitação das APPs de rios

Esta delimitação baseou-se no Art. $2^{\circ}$ do Código Florestal Brasileiro (Lei $n^{\circ}$ 4.771/65), que considera APPs as florestas e demais formas de vegetação natural situadas ao longo de um rio ou de qualquer curso d'água. Para estes, a Resolução CONAMA n ${ }^{\circ} 303$ estabelece uma faixa marginal de largura mínima de 30m (trinta metros) para cursos d'água com até 10m (dez metros) de lâmina d'água. As APPs dos rios foram geradas através de um delimitador de distância (buffer) compondo uma faixa marginal de 30m que foi aplicada ao plano de informação da rede hidrográfica da MBRR.

b) Delimitação das APPs de nascentes

O Art. $2^{\circ}$ do Código Florestal Brasileiro (Lei $n^{\circ} 4.771 / 65$ ) e o Art. $3^{\circ}$, inciso II, da Resolução CONAMA no 303/2002, consideram APPs as florestas e demais formas de vegetação natural situadas nas nascentes, ainda que intermitentes, e nos chamados olhos d'água, qualquer que seja a sua situação topográfica, num raio mínimo de 50m (cinquenta metros) de largura, de tal forma que se proteja a bacia hidrográfica contribuinte. Assim, com base no plano de informação da rede hidrográfica, foi gerado um buffer com raio de $50 \mathrm{~m}$ ao redor de todas as nascentes da área.

c) Delimitação das APPs de lagoas

O Art. $3^{\circ}$, inciso III, da Resolução CONAMA no 303/2002, alínea "b", considera APPs as florestas e demais formas de vegetação natural situadas ao redor de lagos e lagoas naturais, em faixa marginal com metragem mínima de 50m (cinquenta metros) para os que estejam em áreas rurais com até 20 ha (vinte hectares) de superfície. 
d) Delimitação das APPs de reservatórios artificiais

Os reservatórios artificiais são definidos, segundo o Art. $2^{\circ}$, inciso I, da Resolução CONAMA n ${ }^{0}$ 302/2002, como sendo a acumulação não natural de água destinada a quaisquer de seus múltiplos usos. Para aqueles reservatórios não utilizados no abastecimento público ou geração de energia elétrica, com até 20ha (vinte hectares) de superfície e localizados em área rural, o Art. $3^{\circ}$, inciso III, da Resolução CONAMA n ${ }^{\circ} 302 / 2002$, estabelece $15 \mathrm{~m}$ (quinze metros), no mínimo, para a delimitação de sua APP.

Durante a etapa de levantamento do uso das terras, os reservatórios artificiais e as lagoas da MBRR foram digitalizados e posteriormente tiveram suas APPs delimitadas dentro dos critérios estabelecidos pela legislação ambiental. Ao todo, foram mapeados 60 (sessenta) reservatórios artificiais e 7 (sete) lagoas naturais.

\section{iii) Mapeamento dos conflitos de uso nas APPs}

De posse dos mapeamentos dos usos e cobertura das terras e das APPs da MBRR, realizou-se a sobreposição destes, objetivando um mapa síntese que identificasse os conflitos de uso das terras da área de estudo.

Resultados e discussão

Análise do mapeamento de uso e cobertura das terras da MBRR

Considerando a metodologia utilizada, foi possível a identificação e quantificação das seguintes classes de usos e cobertura das terras para a MBRR, conforme a Tabela 1 e o Mapa 1.

Tabela 1 - Quantificação dos usos e cobertura das terras da MBRR

\begin{tabular}{|l|c|c|}
\hline Classe & Área ocupada $\mathbf{( \mathbf { k m } ^ { 2 } \mathbf { ) }}$ & Porcentagem (\%) \\
\hline Cobertura vegetal & 140,6 & 70,0 \\
\hline Loteamento & 34,8 & 17,4 \\
\hline Agricultura & 9,1 & 4,6 \\
\hline Solo exposto & 4,2 & 2,1 \\
\hline Edificação urbana/rural & 2,9 & 1,5 \\
\hline Água & 1,2 & 0,6 \\
\hline
\end{tabular}




\begin{tabular}{|l|c|c|}
\hline Classe & Área ocupada $\mathbf{( \mathbf { k m } ^ { 2 } )}$ & Porcentagem (\%) \\
\hline Indústrias & 0,9 & 0,5 \\
\hline Mineração & 0,8 & 0,4 \\
\hline Reflorestamento & 0,7 & 0,4 \\
\hline Pontos notáveis & Área ocupada $\mathbf{( \mathbf { k m } ^ { 2 } )}$ & Porcentagem (\%) \\
\hline Pista de pouso & 0.38 & 0,2 \\
\hline $\begin{array}{l}\text { Linha de transmissão de energia } \\
\text { da CHESF }\end{array}$ & 3.28 & 1,6 \\
\hline Lixão & 0.22 & 0,1 \\
\hline Rodovias & 1.16 & 0,6 \\
\hline Linha férrea & 0.02 & 0,01 \\
\hline Total & $\mathbf{2 0 0 , 2}$ & $\mathbf{1 0 0}$ \\
\hline
\end{tabular}

Fonte: Pesquisa direta, 2012

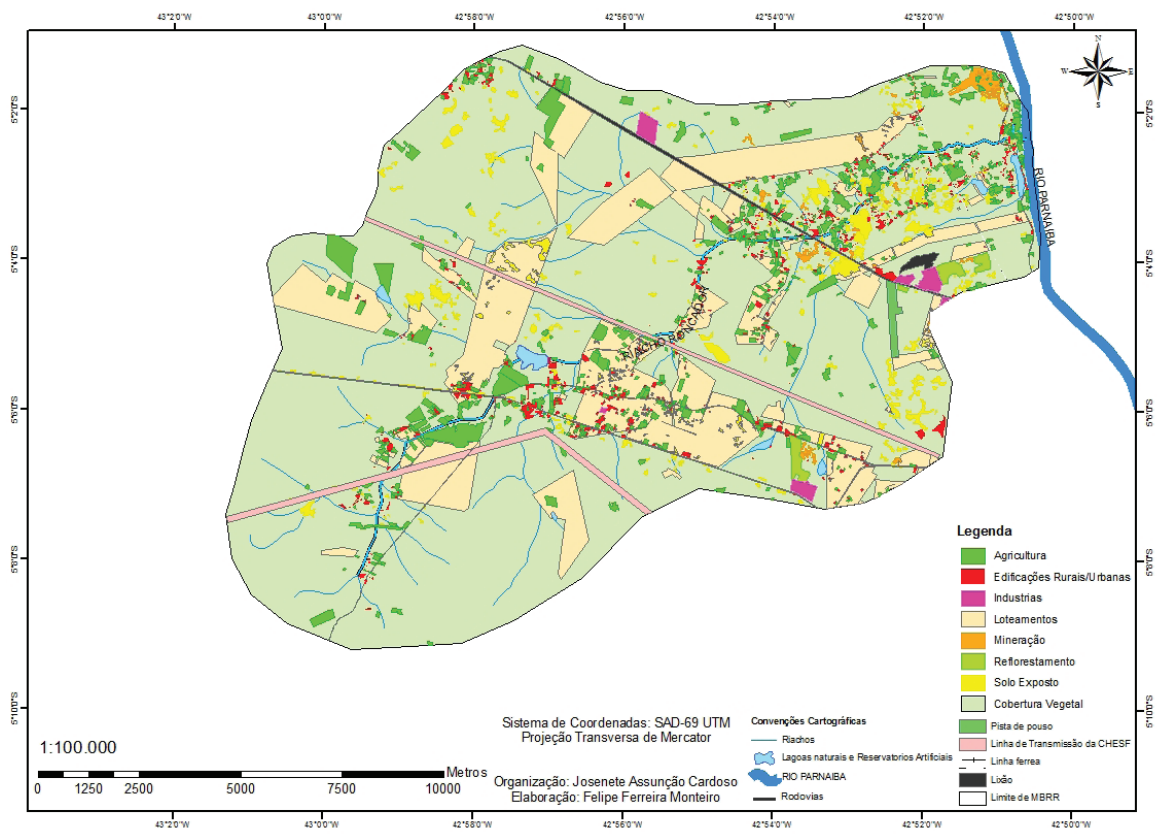

Mapa 1 - Mapeamento dos usos e cobertura das terras da MBRR Fonte: Imagens do satélite GeoEye (Google Earth), de 26/10/2011 
Análise do mapeamento das APPs da MBRR

O mapeamento das APPs da MBRR permitiu identificar uma área total de $9,2 \mathrm{~km}^{2}$, o equivalente a $4,6 \%$ da área total da microbacia. A quantificação das APPs pode ser verificada na Tabela 2.

Tabela 2 - Quantificação das Áreas de Preservação Permanente da MBRR

\begin{tabular}{|l|c|c|c|}
\hline \multicolumn{1}{|c|}{ APP } & Área $\mathbf{k m}^{\mathbf{2}}$ & $\begin{array}{c}\text { \% de APP na } \\
\text { MBRR }\end{array}$ & $\begin{array}{c}\text { \% de cada APP na área } \\
\text { total da APP }\end{array}$ \\
\hline Nascentes & 0,3 & 0,1 & 3,1 \\
\hline Margens & 8,0 & 4,0 & 87 \\
\hline Reservatórios naturais & 0,6 & 0,3 & 6,4 \\
\hline Reservatórios artificiais & 0,3 & 0,2 & 3,5 \\
\hline \multicolumn{1}{|c|}{ Total } & 9,2 & 4,6 & 100 \\
\hline
\end{tabular}

Fonte: Pesquisa direta, 2012

As APPs de margens somaram ao todo $8,0 \mathrm{~km}^{2}$, o que corresponde a $4,0 \%$ da área da microbacia, sendo a APP mais representativa em termos quantitativos.

As APPs em torno dos reservatórios naturais (lagoas) somaram 0,6 $\mathrm{km}^{2}$, o equivalente a $0,3 \%$ da área total da bacia e correspondendo à segunda área de APP mais representativa em extensão.

Já os reservatórios artificiais ocupam $0,3 \mathrm{~km}^{2}$, representando $0,2 \%$ em relação à área total da MBRR. Correspondem à terceira APP mais representativa da área de estudo, representando 3,5\% do total de APPs.

As APPs de nascentes totalizaram, aproximadamente, $0,3 \mathrm{~km}^{2}$, o que representa, aproximadamente, $0,1 \%$ da área de estudo, sendo a APP de menor extensão na área da MBRR.

Como resultado do mapeamento das APPs da microbacia, foi obtido um mapa (Mapa 2) considerando-se as margens e nascentes, reservatórios naturais e artificiais. 


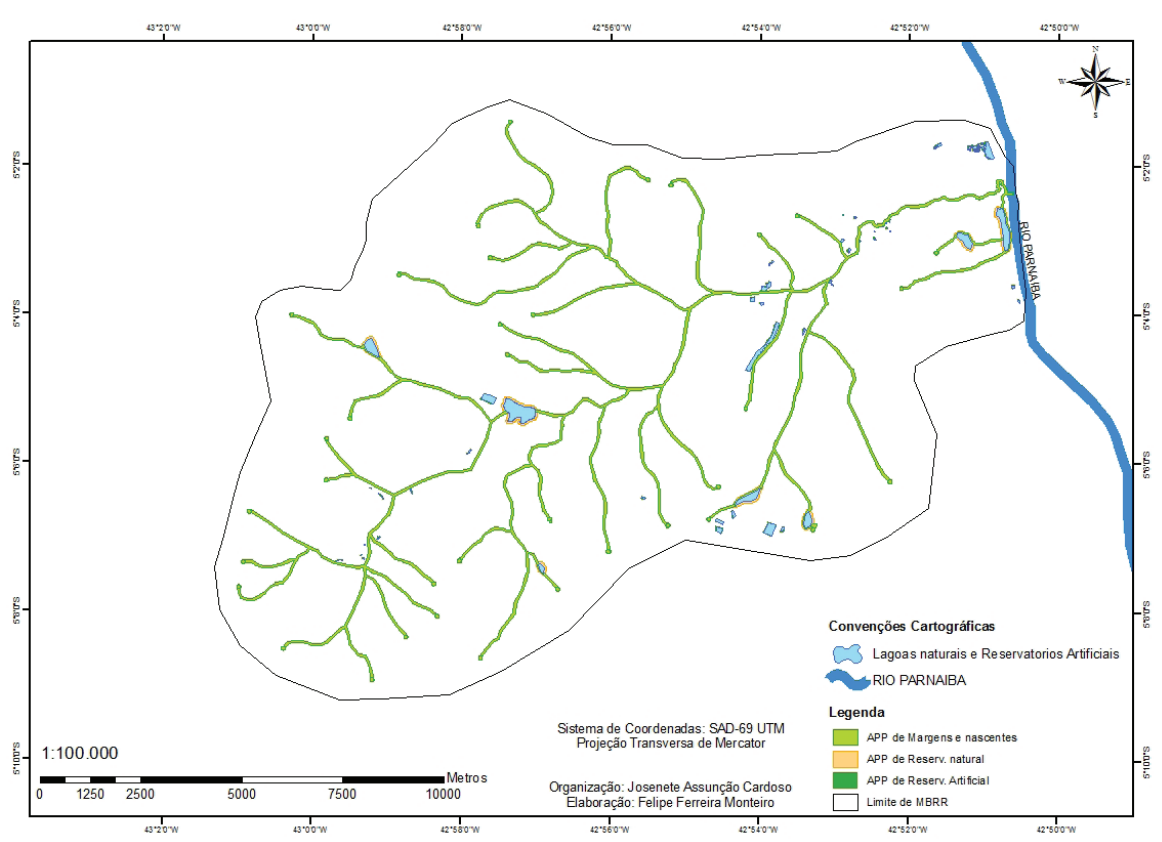

Mapa 2 - APPs mapeadas para a MBRR

Fonte: DSG, Folhas Buriti Cortado (MA), 1974; e Teresina (PI), 1984

Conflitos: uso das terras $x$ APPs da MBRR

Embora a pesquisa tenha identificado uma área total de $9,2 \mathrm{~km}^{2}$ de APPs na MBRR, considerando margens, nascentes, reservatórios naturais (lagoas) e reservatórios artificiais, não significa que elas estejam integralmente preservadas segundo recomendam as legislações pertinentes.

Assim, considerando as normas do Código Florestal e Resoluções do CONAMA já citadas, foram quantificadas as APPs em desacordo com os usos desenvolvidos na área da MBRR. A realização dessa quantificação permitiu constatar o estado de preservação da vegetação ciliar da microbacia, bem como identificar e mensurar os conflitos decorrentes dos usos dessas áreas que deveriam, por lei, estar preservadas, conforme Tabela 3. 
Tabela 3 - Total de APPs da MBRR, APPs preservadas e APPs em desacordo com a legislação ambiental

\begin{tabular}{|c|c|c|c|c|c|c|}
\hline \multirow[t]{2}{*}{ APPs } & \multicolumn{2}{|c|}{ Total } & \multicolumn{2}{|c|}{$\begin{array}{c}\text { APP } \\
\text { preservada }\end{array}$} & \multicolumn{2}{|c|}{$\begin{array}{c}\text { APP em } \\
\text { desacordo com a } \\
\text { legislação ambiental }\end{array}$} \\
\hline & $\left(\mathrm{km}^{2}\right)$ & $(\%)$ & $\left(\mathrm{km}^{2}\right)$ & $(\%)$ & $\left(\mathrm{km}^{2}\right)$ & $(\%)$ \\
\hline Nascentes & 0,3 & 3,1 & 0,2 & 2,3 & 0,1 & 0,8 \\
\hline Margens & 8,0 & 87 & 5,8 & 62,8 & 2,2 & 24,3 \\
\hline Reservatórios naturais & 0,6 & 6,4 & 0,5 & 5,3 & 0,1 & 1,1 \\
\hline Reservatórios artificiais & 0,3 & 3,5 & 0,2 & 1,7 & 0,2 & 1,7 \\
\hline Total & 9,2 & 100 & 6,7 & 72,1 & 2,6 & 27,9 \\
\hline
\end{tabular}

Fonte: Pesquisa direta, 2012

Da área total de APPs presentes na MBRR $\left(9,2 \mathrm{~km}^{2}\right), 2,6 \mathrm{~km}^{2}$ foram identificados como em desacordo com a legislação ambiental, correspondendo a 27,9\% da área total de APP, conforme Tabela 3. Os dados dessa tabela permitem inferir que:

- do total de APPs de nascentes presentes na área (3,1\%), 0,8\% encontra-se em desacordo com a legislação ambiental, representando o percentual total de APPs de nascentes em conflito de uso;

- do total de APPs de margens presentes na área (87\%), 24,3\% encontram-se em desacordo com a legislação ambiental, representando o percentual total de APPs de margens em conflito de uso;

- do total de APPs de reservatórios naturais presentes na área (6,4\%), $1,1 \%$ encontra-se em desacordo com a legislação ambiental, representando o percentual total de APPs de reservatórios naturais em conflito de uso;

- do total de APPs de reservatórios artificiais presentes na área (3,5\%), 1,7\% encontra-se em desacordo com a legislação ambiental, representando o percentual total de APPs de reservatórios artificiais em conflito de uso.

De modo geral, constata-se o predomínio de usos inadequados nas APPs de margens. Esses usos em desrespeito à legislação ambiental representam $24,3 \%$.

De acordo com dados sobre os usos e cobertura das terras, verificou-se ainda que a especulação imobiliária exerce uma forte pressão na área da MBRR, espaço preferido para a aquisição/construção de imóveis 
devido à proximidade da água. Essa característica favorece a instalação dessas construções, prioritariamente residenciais e para fins de lazer, bem próximas aos cursos d'água. A pequena agricultura é, também, favorecida pela proximidade da água dos cursos, justificando a porcentagem mais elevada para este conflito (24,3\%).

Assim, considerando as APPs da microbacia e os conflitos decorrentes do uso das terras que deveriam estar preservadas, foi possível quantificar o total de áreas preservadas e o total de áreas em desacordo com a legislação ambiental, conforme Tabela 4.

Tabela 4 - APPs preservadas e APPs em desacordo com a legislação ambiental

\begin{tabular}{|l|c|c|}
\hline APPs & $\mathbf{K m}^{\mathbf{2}}$ & $\mathbf{( \% )}$ \\
\hline Preservadas & 6,6 & 72,1 \\
\hline Em desacordo com a legislação ambiental & 2,6 & 27,9 \\
\hline Total & 9,2 & 100 \\
\hline
\end{tabular}

Fonte: Pesquisa direta, 2012

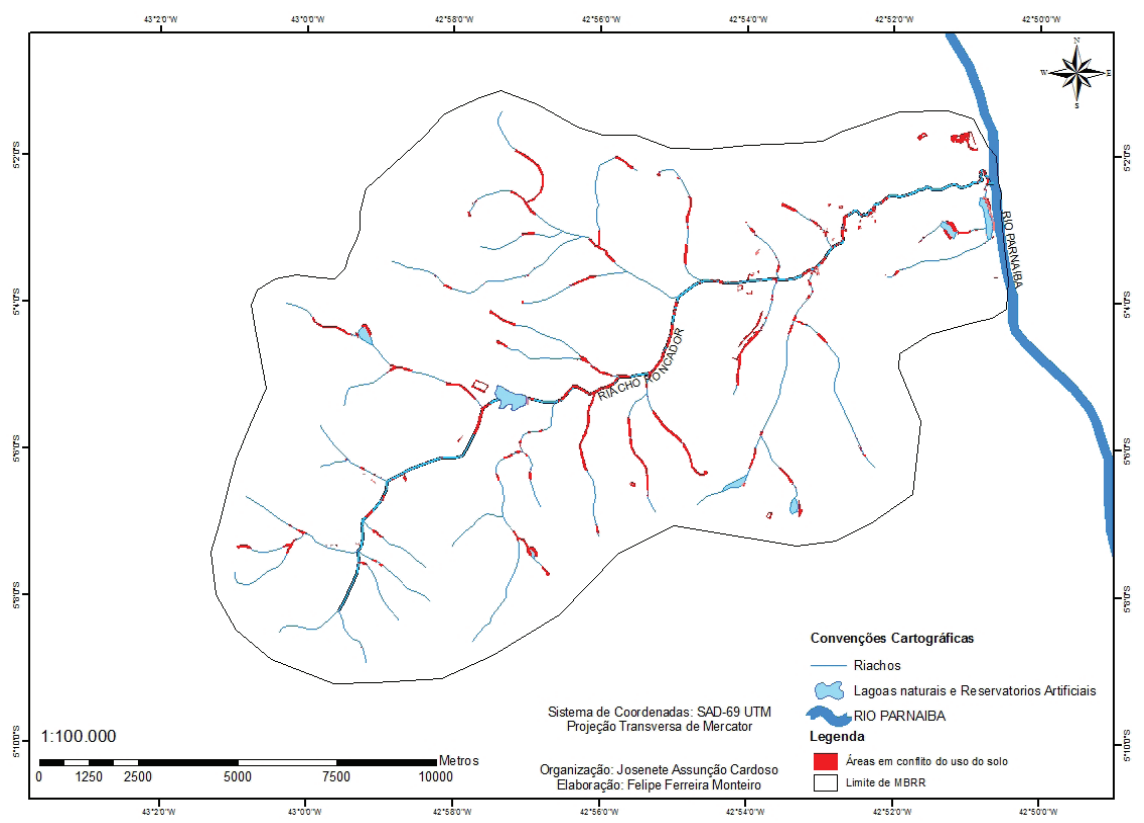

Mapa 3 - APPs: conflitos de uso das terras da MBRR

Fonte: DSG, Folhas Buriti Cortado (MA), 1974; e Teresina (PI), 1984;

Imagem do Google Earth, de 26/10/2011 
Os dados da Tabela 4 apontam para uma microbacia com $72,1 \%$ de sua área de APPs preservadas ou de acordo com as recomendações da legislação ambiental. O estado de preservação das mesmas pode ser observado no Mapa 3, que traz o balanço das APPs preservadas e APPs em desacordo com a legislação ambiental.

Diante do panorama crescente de degradação ambiental, em todo o país, e do avanço das atividades antrópicas sobre áreas inapropriadas, dentre elas as APPs, pode-se afirmar que a MBRR encontra-se em situação "confortável”, já que a porcentagem de APPs da microbacia em desacordo com a legislação ambiental é relativamente baixa: 27,9\% do total da área.

\section{Considerações finais}

Considerando os critérios de preservação estabelecidos pelo Código Florestal e pelas Resoluções do CONAMA, observou-se que a supressão da vegetação das APPs, seguida do uso destas áreas para os mais diversos fins, constituem uma realidade na área de estudo.

A pesquisa revelou que $9,2 \mathrm{~km}^{2}$ da área da MBRR correspondem a APPs. Destes, 6,6 km² estão preservados e 2,6 km² estão em desacordo com a legislação ambiental.

Considerando a baixa porcentagem de APPs em desacordo com a legislação ambiental, pode-se dizer que a MBRR encontra-se em uma situação "confortável" diante dos crescentes índices de degradação em todo o país. Por outro lado, esse fato revela-se preocupante na medida em que se considera a função ambiental destas áreas mediante o avanço do crescimento urbano sobre as mesmas, como também o fato de o abastecimento do município de Timon depender da captação de água subterrânea, além do comprometimento da área em relação à prática do lazer (identidade local) através dos balneários, identificados como um potencial para o fomento da economia do município. A preservação das APPs da MBRR é condição primária para a existência e qualidade desses usos.

Assim, os resultados chamam a atenção para que os vetores de crescimento urbano atuais e a anexação de áreas agrícolas respeitem os níveis de conservação da área; ao mesmo tempo, recomenda-se a adequação das APPs em conflito de uso às recomendações da legislação pertinente, garantindo sua preservação e função ambientais.

As geotecnologias empregadas no mapeamento das APPs da MBRR foram ferramentas fundamentais, uma vez que possibilitaram o mapeamento e aquisição de informações de áreas remotas da microbacia, bem 
como o seu enquadramento nos critérios de preservação estabelecidos pela legislação.

Diante do panorama atual de demanda por moradia, espera-se que os dados e informações gerados pela presente pesquisa convertam-se em subsídios que auxiliem os profissionais responsáveis pela fiscalização dessas áreas especiais e os órgãos competentes a gerir e intermediar os diversos conflitos relacionados a elas.

\section{Referências}

BRASIL. Lei $n^{\circ}$ 4.771, de 15 de setembro de 1965. Institui o Código Florestal. Diário Oficial da União, Brasília (DF), 16 de setembro de 1965. Disponível em: <http:// www.planalto.gov.br/ccivil/LEIS/L4771.htm>. Acesso em: 19 set. 2011.

. Conselho Nacional do Meio Ambiente. Resolução CONAMA no 302, de 20 de março de 2002a. Dispõe sobre os parâmetros, definições e limites de Áreas de Preservação Permanente de reservatórios artificiais e o regime de uso do entorno. Diário Oficial da União, Brasília (DF), 13 de maio de 2002. Disponível em: <http:// www.mma.gov.br/port/Conam a/res /res02/res30202.html>. Acesso em: 15 ago. 2012.

. Conselho Nacional do Meio Ambiente. Resolução CONAMA no 303, de 20 de março de 2002b. Dispõe sobre parâmetros, definições e limites de Áreas de Preservação Permanente. Diário Oficial da União, Brasília (DF), 13 de maio de 2002. Disponível em: <http://www.mma.gov.br/port/conama/res/res02/res30302. html>. Acesso em: 15 ago. 2012.

. Ministério das Minas e Energia. Secretaria Geral. Projeto RADAMBRASIL. Levantamento de recursos naturais. Folha SB 23 Teresina e Folha SB 24 Jaguaribe. Rio de Janeiro, 1973.

. Legislação Brasileira sobre Meio Ambiente. 3. ed. Brasília: Câmara dos Deputados, Edições Câmara, 2010.

. Companhia de Desenvolvimento dos Vales do São Francisco e do Parnaíba

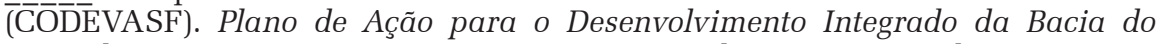
Parnaíba (PLANAP). Síntese executiva. Território dos Cocais. Brasília (DF), 2006. 1 CD-ROM.

CORREIA FILHO, F. L. et. al. Projeto Cadastro de Fontes de Abastecimento por Água Subterrânea, Estado do Maranhão: relatório diagnóstico do município de Timon. Teresina: CPRM - Serviço Geológico do Brasil, 2011.

EMPRESA BRASILEIRA DE PESQUISA AGROPECUÁRIA (EMBRAPA). Levantamento exploratório - reconhecimento de solos do Estado do Maranhão. Embrapa Solos, EUP/Recife, 1986. Disponível em: <http://www.uep. cnps.embrapa.br/solos/index.php?link=ma>. Acesso em: 14 maio 2012.

HORTON, R. E. Erosional development of streams and their drainage basins: hydrophysical approach to quantitative morphology. Bulletin of the Geological Society of America, v. 56, n. 2, p. 275-370, 1945. 
INSTITUTO BRASILEIRO DE GEOGRAFIA E ESTATÍSTICA (IBGE). Zoneamento geoambiental do Estado do Maranhão. Diretrizes gerais para a ordenação territorial. Salvador: IBGE, 1997.

. Cartas Topográficas. Folhas: Teresina (PI). SB-23 X-D-II/886. Brasília: $\overline{\mathrm{IB}} \overline{\mathrm{G}} \overline{\mathrm{E}}$, 1984 (Escala 1:100.000). Disponível em: www.ibge.gov.br. Acesso em: 18 abr. 2011.

. Cartas Topográficas. Folhas: Buriti Cortado (MA) SB-23 X-D-I/885. Brasília: IBGE, 1974 (Escala 1:100.000). Disponível em: www.ibge.gov.br. Acesso em: 18 abr. 2011.

. Manual Técnico de Uso da Terra. Rio de Janeiro: Fundação Instituto Brasileiro de Geografia e Estatística (FIBGE), 2006. 91 p. (Manuais técnicos em Geociências, $\mathrm{n}^{\mathrm{o}}$ 7). Disponível em: <http://geoftp.ibge.gov.br/documentos/recursos _naturais/manuais_tecnicos/manual_uso_da_terra.pdf $>$. Acesso em: 23 ago. 2012. MAGAlHÃES, C. S.; FERREIRA, R. M. A. Áreas de Preservação Permanente em uma microbacia. Informe Agropecuário, Belo Horizonte, v. 21, n. 207, p. 82-94, nov./dez. 2000.

MARANHÃO. Instituto Maranhense de Estudos Socioeconômicos e Cartográficos (IMESC). Desenvolvimento econômico recente do Maranhão: uma análise do crescimento do PIB e perspectivas. São Luís (MA), 2008.

MARANHÃO. Prefeitura Municipal de Timon. Plano Estratégico de Desenvolvimento Sustentável de Timon. Timon (MA), 2002.

MOREIRA, A. M. et al. Uso de imagens do Google Earth capturadas através do software stitch map e do TM/Landsat-5 para mapeamento de lavouras cafeeiras - nova abordagem metodológica. In: XV Simpósio Brasileiro de Sensoriamento Remoto. Curitiba (PR), 2011.

NOVO, E. M. L. M. Sensoriamento remoto: princípios e aplicações. São Paulo: Edgard Blücher, 2010.

ZANATTA, F. A. S.; LEAL, A. C.; PIROLI, E. L. Análise do uso e cobertura das terras das Áreas de Preservação Permanente ao longo do canal principal do baixo curso do rio Paranapanema. Revista Ciência Geográfica, v. XVI (1), jan./dez. 2012.

Josenete Assunção Cardoso - Graduada em Geografia pela Universidade Estadual do Piauí - Especialista em Espaço, Turismo e Meio Ambiente e Mestre em Geografia pela mesma universidade - Professora do quadro permanente da Secretaria de Educação do Estado do Piauí e Secretaria de Educação do Estado do Maranhão.

Claudia Maria Sabóia de Aquino - Graduada em Geografia pela Universidade Federal do Piaú - Mestre em Desenvolvimento e Meio Ambiente pela Universidade Federal do Ceará - Doutora em Geografia pela Universidade Federal de Sergipe - Professora Adjunta da Universidade Federal do Piauí. 